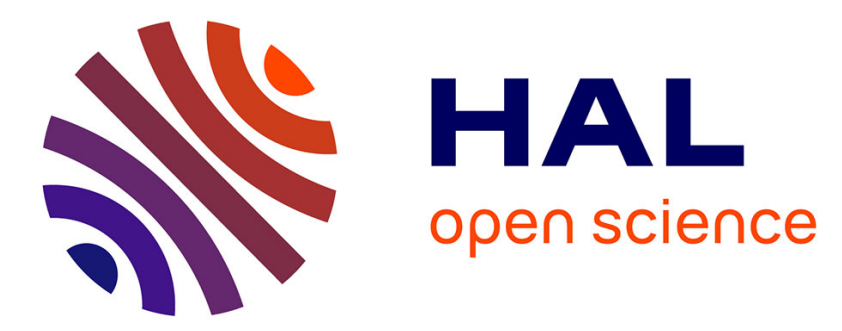

\title{
Including the Evaluation of the Compliance to Delivery Dates into a Performance Analysis Concept
}

Hendrik Jähn

\section{To cite this version:}

Hendrik Jähn. Including the Evaluation of the Compliance to Delivery Dates into a Performance Analysis Concept. 16th Working Conference on Virtual Enterprises (PROVE), Oct 2015, Albi, France. pp.526-534, 10.1007/978-3-319-24141-8_49 . hal-01437918

\section{HAL Id: hal-01437918 \\ https://hal.inria.fr/hal-01437918}

Submitted on 17 Jan 2017

HAL is a multi-disciplinary open access archive for the deposit and dissemination of scientific research documents, whether they are published or not. The documents may come from teaching and research institutions in France or abroad, or from public or private research centers.
L'archive ouverte pluridisciplinaire HAL, est destinée au dépôt et à la diffusion de documents scientifiques de niveau recherche, publiés ou non, émanant des établissements d'enseignement et de recherche français ou étrangers, des laboratoires publics ou privés. 


\title{
Including the Evaluation of the Compliance to Delivery Dates into a Performance Analysis Concept
}

\author{
Hendrik Jähn \\ Chemnitz University of Technology, Department of Economic Sciences, Thüringer Weg 7 \\ 09126 Chemnitz, Germany, hendrik.jaehn@wirtschaft.tu-chemnitz.de
}

\begin{abstract}
The delivery date is one of the most important performance parameters of a business contract. In order to guarantee the customers' satisfaction and sustainable success it is essential to keep the fixed delivery date. Therefore a performance measurement system needs to be applied. In the following a specific approach for the performance analysis for Virtual Enterprises is introduced. Hereby both the comprehensive approach for performance analysis and the procedure for the evaluation of the compliance to delivery dates are considered. This concept allows an adaptive applicability which is necessary to support the short-term management of order-specific configured Virtual Enterprises within smart networked environments.
\end{abstract}

Keywords: Virtual Enterprise, Performance Analysis, Delivery Date, Collaborative Network Model.

\section{Motivation}

The agreement of an exact delivery date represents an essential part in a contract between supplier and customer. Adherence of the delivery date should have highest priority for the supplier as deviations from the agreed delivery date often entail farreaching consequences for the buyer. This may also lead to negative consequences for the supplier, e.g. in form of contractual penalties or loss of customers. In connection to Virtual Enterprises / collaborative systems, adherence of the delivery date gets even higher importance by a particularly close and time-referenced cooperation.

Deviations of the delivery date represent a serious problem field as buffer time can hardly be planned. In that context the research question arises how to analyze and evaluate the adherence of the delivery date in networked production structures. As a relevant research methodology it represents one part of a comprehensive approach for the analysis of enterprise-related performances. That approach allows a consideration of different performance parameters, e.g. product quality, response time, price and soft-facts. The analysis is realized related to value-added processes. That means conduction is done separately for each production process or transaction. This form of modeling represents an essential precondition for the value-added-related performance analysis. As major research objectives are to be mentioned a high degree of flexibility and adaptability in combination with clear rules for the evaluation. 


\section{Regulatory Framework}

\subsection{Towards a Performance Analysis Approach}

For the realization of the performance analysis in Virtual Enterprises a comprehensive model has been developed [1]. That approach both includes value-added process neutral and value-added process-related process steps. The structure of the model and the interdependencies of the steps are displayed in Figure 1.

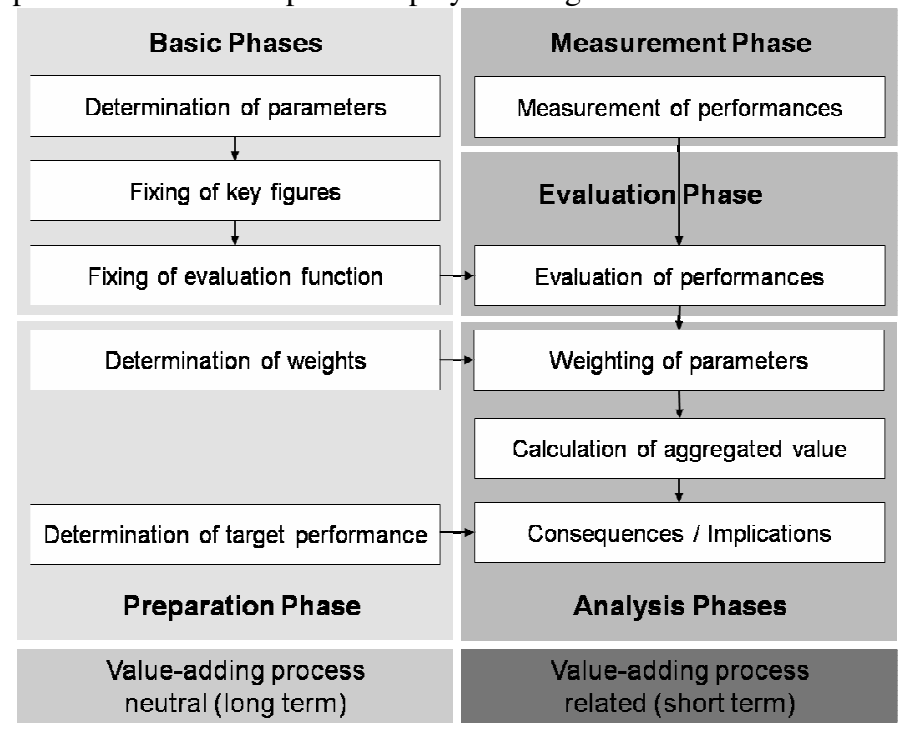

Fig. 1. Performance Analysis Approach.

The performance analysis approach includes the measurement, evaluation and analysis of relevant services performed by an enterprise operating in a collaborative network based on selected performance parameters. Herein, special attention is paid to aspects relating to one specific value-added process. This operational perspective allows acquiring cognitions about services performed by an enterprise after finishing a value-added process. Hereby, consequences, e.g. concerning the allocation of profit shares can be deduced in case of an unsatisfactory performance of an enterprise [2].

The primary task of the performance analysis approach is to determine the degree of services performed by an enterprise. For this purpose, primarily quantitative methods are applied. The result is considered by the implementation of incentive and sanction mechanisms. Herein, methods for the calculation of profit shares play a specific role. Within this context, it is necessary to analyze the services performed by the enterprises based on selected and relevant performance parameters [3].

The determination of performance parameters is realized by the involvement of an adapted Balanced Scorecard. Performance parameters considered within the performance analysis are the price, date of delivery, response time, product quality, reliance and cooperation climate [1]. The last two parameters form soft factors, whose 
perceptions primarily have to be quantified through appropriate methods. Each of those performance parameters is characterized by a specific key figure. For the evaluation of the services performed, specific evaluation functions, similar to utility functions, are applied. In order to regard their different relevancies, the evaluations can be weighted individually. By multiplying weighting and level of utility, aggregated utility values are calculated, similar to the value benefit analysis. The sum of the aggregated utilities of all performance parameters represents the actual performance. This can be compared to the target performance. Hereof, an enterprisespecific degree of target fulfillment is calculated. This allows a deviation of consequences e.g. incentives and sanctions. Consecutively, performance analysis is demonstrated in detail by considering the performance parameter "date of delivery".

\subsection{Literature Research}

As already mentioned, focus is put on the integration of performance parameter "date of delivery". Within a a comprehensive approach for the enterprise-related performance analysis, the aim is to analyze the degree of service provision. This means that a deviation of the realized from the agreed date of delivery needs to be recorded correctly. For this purpose, monitoring and workflow management instruments are applied. Subsequently, the evaluation analysis is realized by an adapted form of the value benefit analysis in combination with selected mathematical methods. First of all, an appropriate key figure including evaluation function has to be determined for the performance parameter "date of delivery". Within the context of a collaborative network, the date of delivery does not present the final date of delivery of the finished product to the customer, but the respective completion date at the analyzed enterprise. In consideration of possible effects of upstream enterprises within the collaborative network, an extended and differentiated problem to consider arises. Approaches for the evaluation of performances within networked organization structures are available and have been published in a quite unmanageable number.

In this context, one forerunner is Neely, who deals with questions concerning the performance measurement in supply chains and networks [4]. Herein, analyses can be arranged from several perspectives [5]. In general, however, it has been observed that primarily medium- and long-term approaches are suggested. Background for this is the financial focus of those approaches with regard to external effects of the company. During the development of those approaches, it is often reverted to the Balanced Scorecard, followed by an adoption of the same in a modified form considering supply chains or networks [6],[7],[8]. A more specific focus on performance indicators for collaborative networks based on collaboration benefits can be found in [9]. Most networks exist long term whereas virtual enterprises represent the cooperation of several enterprises for completing a value-added process. This more relevant perspective is focused by Westphal et al. by investigating methodologies of measuring the collaborative performance in virtual enterprises [10]. However, this publication primarily considers soft-facts and therefore is less relevant here. Another publication in that field is [11] which introduces a case study for delivery performance measurement. 


\section{The Performance Parameter "Date of Delivery"}

\subsection{Identification of the Key Figure "Adherence to Delivery Date"}

The determination of the key figure "adherence to delivery date" respectively "deviation to delivery date" of an enterprise occurs through an evaluation in consideration of the cause or the initiator of the deviation. In general, it has to be distinguished whether the delivery of an enterprise did occur early, on time or delayed. The deviation of the planned / agreed date of delivery $l_{i}^{a}$ from the realized date of delivery $l_{i}^{r}$ results from the difference of both values and is described as (local) deviation to delivery date or adherence to delivery date $\Delta l_{i}^{l}$, which leads to equation (1):

$$
\Delta l_{i}^{l}=l_{i}^{r}-l_{i}^{a}
$$

$\Delta l_{i}^{l}$ is an enterprise-related figure. Depending on the development of the delivery situation, the consequence is, that in case of $\Delta l_{i}^{l}>0$ the delivery is considered as delayed, for $\Delta l_{i}^{l}=0$, the delivery arrived on time and for $\Delta l_{i}^{l}<0$, the delivery occurred early. That interpretation is based on the method of cumulative quantities. That means a delivery on the $20^{\text {th }}$ day while having an agreed delivery date on the $15^{\text {th }}$ day can be interpreted as a delay of 5 days $(20-15=5)$. By the application of this method, it is possible to calculate an absolute value for the performance analysis. The delivery dates or appointments have to be offset against each other. The decision about the metric should be made depending on the designated accurateness. According to the chosen metric (week, day, hour, minute), the statements concerning the deviation are rough (week) or comparatively accurate (minute) by trend.

To stress the significance of the performance figure "deviation to delivery date" of an enterprise and to allow an activity-based evaluation likewise in the context of the performance analysis, it is necessary to rectify the locally caused delivery adherence of an enterprise $\Delta l_{i}^{l}$ by possible delays by enterprises, which accomplish a previous process step. These enterprises are denoted as "upstream enterprises" $(i-1)$ in the collaborative network. It is therefore possible that an enterprise will, only because of one late delivery of one or more upstream enterprises, also deliver delayed. Due to this fact, the "upstream delay" $\Delta l_{i}^{v}$ has to be considered as a further influencing value for the performance analysis of that parameter. In the following, the possibilities for the determination of adherences to delivery dates of upstream enterprises are discussed.

If a value-added chain is considered, in general there is only one upstream company (linear process) existent, so that the relevant deviation to delivery date $\Delta l_{i}^{v}$ complies with the deviation to delivery dates of the upstream company $\Delta l_{i-1} l$. In this case, it is valid:

$$
\Delta l_{i}^{l}=\Delta l_{i-1}^{v}
$$

Here value $\Delta l_{i-1}{ }^{l}$ describes the schedule variance of the upstream enterprise. In case several upstream companies have to be considered (networked process), the specific local delivery delays $\Delta l_{i-1}{ }^{l}$ have to be taken into account for all upstream enterprises $(i-1)$. The delay $\Delta l_{i}^{v}$, which finally has to be considered herein, is calculated out of the maximum of delays of all enterprises, which are directly preceded within the value- 
added process. This highest delivery delay of a direct forerunner $\max \left(\Delta l_{i-1}{ }^{l}\right)$ represents the delay, which has to be considered for the currently observed enterprise $\Delta l_{i}^{v}$. The following equation is valid:

$$
\Delta l_{i}^{v}=\max \left(\Delta l_{i-1}^{l}\right) .
$$

After determination of the locally relevant delivery date variances of an enterprise $\Delta l_{i}^{l}$ as well as the delivery date variance of direct upstream enterprises $\Delta l_{i}^{v}$, which has to be included for a value correction, the deviation to delivery dates $\Delta l_{i}$, which is the one important input factor for the performance analysis, can be calculated as follows:

$$
\Delta l_{i}=\Delta_{i}^{l}-\Delta l_{i}^{v}
$$

The value deviation to delivery dates equals the performance figure for the performance parameter delivery date and forms one input variable for the performance analysis. At this stage, one can ask for possible reasons for a schedule variance $\Delta l_{i}$ caused by an enterprise. The starting point for arguing is the assumption that within the context of the tender preparation, each enterprise determines an orderspecific processing time within the production control, which can be expressed by a corresponding completion date of production. The processing time, which forms the basis of the delivery date fixed in an offer, is $t_{i}^{P T a}$. A schedule variance $\Delta l_{i}$, which was caused by the enterprise itself, is expected in cases where the eventually realized processing time of the tender $t_{i}^{P T r}$ deviates from the planned processing time $t_{i}^{P T a}$ during the value added process. By this procedure, $\Delta l_{i}$ can be calculated alternatively as follows:

$$
\Delta l_{i}=t_{i}^{P T r}-t_{i}^{P T a}
$$

Due to the fact that the calculation of the deviation to delivery date of an enterprise is only possible if all delivery dates within the network are known (both offer dates and realized dates), the collection of all performance figures has to be accomplished after completion of the value-added process.

\subsection{Measurement of the Key Figure "Adherence to Delivery Date"}

By the application of the calculation formulas for the performance figure "(corrected) deviation to delivery date" $\Delta l_{i}$, the result is an accurate time specification. For further processing, in principle two ways are conceivable. On the one hand, it is possible to work with the accurate values of the company-specific schedule variance, which however causes a considerable calculating effort. A further possibility is a provision for the deviation to delivery dates in form of tendential schedule variances. This approach is introduced in the following.

The evaluation function for adherence to delivery dates $f_{i}\left(\Delta l_{i}\right)$ used for calculating the evaluation credits $x_{i}^{l}$ in this approach only considers the influencing factor of the corrected (actually caused) schedule variance $\Delta l_{i}$, whereas local delay $\Delta l_{i}^{l}$ and upstream delay $\Delta l_{i}^{v}$ are input values. 
To allow an evaluation / analysis, all potential combinations of those three influencing factors have to be identified. This is to evaluate the practical relevancy. Figure 2 introduces all combinations of the three values $\Delta l_{i}^{v}, \Delta l_{i}^{l}$ and $\Delta l_{i}$ which are possible. Consequently, not the accurate deviation serves as the main distinction criterion herein, but only the kind of deviation by trend, whereas "+" signifies a late delivery, “-“ an early delivery and "0” represents a delivery in time.

\begin{tabular}{|c|c|c|l|}
\hline$\left(\Delta \mathbf{l}_{\mathbf{i}}\right)$ & $\left(\Delta \mathbf{l}_{\mathbf{i}}\right)$ & $\left(\Delta \mathbf{l}_{\mathbf{i}}{ }^{\mathrm{N}}\right)$ & \\
\hline 0 & 0 & 0 & all deliveries are on time \\
\hline 0 & 0 & - & not possible \\
\hline 0 & 0 & + & not possible \\
\hline 0 & - & 0 & not possible \\
\hline 0 & - & - & early delivery, stable conditions \\
\hline 0 & - & + & not possible \\
\hline 0 & + & 0 & not possible \\
\hline 0 & + & - & not possible \\
\hline 0 & + & + & unchanged delay \\
\hline- & 0 & 0 & not possible \\
\hline- & 0 & - & not possible \\
\hline- & 0 & + & delay has been eliminated, exact delivery date now \\
\hline- & - & 0 & enterprise is the first one to cause an early delivery \\
\hline- & - & - & incoming early delivery, rate has been increased \\
\hline- & - & + & delay has been changed into a too early delivery \\
\hline- & + & 0 & not possible \\
\hline- & + & - & not possible \\
\hline- & + & + & reduced delay but still delay \\
\hline+ & 0 & 0 & not possible \\
\hline+ & 0 & - & an early delivery has been changed into a delivery on time \\
\hline+ & 0 & + & not possible \\
\hline+ & - & 0 & not possible \\
\hline+ & - & - & incoming early delivery, still early but with a reduced rate \\
\hline+ & - & + & not possible \\
\hline+ & + & 0 & enterprise is the first one to cause a delay \\
\hline+ & + & - & despite an early delivery enterprise has caused a delay \\
\hline+ & + & + & delay has been increased \\
\hline & & & Fig 2 Possible combinations of the input variables. \\
\hline
\end{tabular}

Fig. 2. Possible combinations of the input variables.

Starting from these theoretic possibilities, only practically relevant situations are contemplated in the following analysis. This concerns situations which are highlighted in grey.

\subsection{Evaluation of the key figure "Adherence to Delivery Date"}

As it has already been shown, an adjusted value can be determined for the considered value-added process and the analyzed enterprise for the adherence of the delivery date $\Delta l_{i}$. This value has to be transferred to a score evaluation afterwards. Therefore and formally stated, a relation between the adherence to the delivery date $\Delta l_{i}$ and the score evaluation $x_{i}^{l}$ can be formulated in the form of a mathematic function. This function is called evaluation function. It has to be seen as a utility function in the context of the value benefit analysis.

The method of Lagrange interpolation is intended to determine exact (utility-) functions out of selected relevant combinations of $\Delta l_{i}$ and $x_{i}^{l}$ given. This procedure allows the generation of a polynomial, which leads through an arbitrary number of points. First of all, selected distinctive points of the function, which has to be 
determined, need to be defined. Here it has to be considered that the values of the abscissa ( $x$-values) are distributed all about the same considered interval, whereas the probability is increased that a function is generated, which is consistent with the desired process. Normally, the selection of four credits is adequate, whereas two credits shall reflect the relevant exceptional conditions. In a concrete way, full marks are given for exact date adherence taken as an example, while for an exceeding of the maximum justifiable deviation, 0 credits are assigned. The value of 10 is usually given as full marks. Division within the parameters of 0 to 10 makes a significant evaluation possible. At this point, all relevant combinations have been assigned to adequate groups. This leads to a specific evaluation function (6):

$$
f_{i}\left(\Delta l_{i}\right)=x_{i}^{l} .
$$

Adherence to the date of delivery can be interpreted as one essential characteristic of making delivery of an enterprise, as missing this target will have effects on all downstream processes, so that an influence on the due-date of the final product can be expected.

One possibility for a simplified consideration is the formation of different groups. According to the present modeling, there is an evaluation function, which may be applied for all kinds of combinations of the input parameters from Figure 2. Seen from a practical perspective, not all kinds may be treated and evaluated the same way. So, it is important for the evaluation whether delays were caused by an enterprise or if existing delays were reduced. Therefore, it is recommended to introduce grouping, which can be evaluated in a similar way but regarding the specific situation. The division into different groups allows for a more detailed observation with a high flexibility regarding potential adjustments. However, a specific evaluation function has to be modeled then for each existing group. This can easily be achieved by means of the Lagrange interpolation.

\subsection{Analysis of the Key Figure "Adherence to Delivery Date"}

After determining the score evaluation of the performed service, it can be incorporated into the performance analysis. For this purpose, the score evaluations of the remaining performance parameters have to be known. To be able to consider the different meaning of the single performance parameters regarding the whole evaluation, performance parameter related weightings are included.

An actual value of making delivery is calculated from the weighted sum of the single score evaluations, which is then compared to a target value of making delivery. This comparison then allows for a statement if an enterprise has delivered the desired performance in a certain value-added process. If this is not the case, there is the possibility that negative consequences occur for the company, for instance in form of sanction payments or reduced share in profits. However, this subject matter shall not be enlarged upon at this point, as this concerns tasks relating to the whole performance analysis model. 


\section{Conclusions}

An approach for the evaluation and analysis of the performance parameter "delivery date" and its key figure "adherence to delivery dates" has been introduced. It was developed for enterprises operating in Virtual Enterprises. Major advantages are the consideration of different classifications ("groups") for possible scenarios and the development of specific evaluation functions. They allow modeling a calculation scheme dependent on the degree of meeting the agreed delivery date.

The approach represents a quantitative model. Similar models have also been developed for further performance parameters. Therefore, a universal concept for a performance analysis, which relates to the value-added process, is available. This approach allows a complete and comprehensive analysis of the service performed by an enterprise operating in a collaborative network. The introduced approach has consistently been modeled and therefore, it allows for an application related to practical requirements. One limitation is the static character of the approach.

Efforts regarding a realization of the approach from an information-technical point of view as well as its integration into the comprehensive model of the performance analysis are being made currently and represent the challenge for future works.

\section{References}

1. Jähn, H.: Value-added process-related performance analysis of enterprises acting in cooperative production structures. Production Planning \& Control 20, 178--190 (2009)

2. Jähn, H.: A comprehensive Approach for the Management of Virtual Enterprises including Performance Analysis, Provision of Incentives and Allocation of Income. In: CamarinhaMatos, L.M. and Scherer R.J. (Eds.): PRO-VE 2013, IFIP AICT 408, pp. 147--155 (2013)

3. Jähn, H.: Fundamentals for the Development of a Performance Analysis Approach in Collaborative Networks. In: Camarinha-Matos, L.M. and Afsarmanesh, H. (Eds.): PRO-VE 2014, IFIP AICT 434, pp. 521--533 (2014)

4. Neely, A. (ed.): Business Performance Measurement, $2^{\text {nd }}$ Ed., Cambridge University Press, Cambridge (2007)

5. Chendall, R.H., Langfield-Smitz, K.: Multiple Perspectives of Performance Measures. European Management Journal 25, 266--282 (2007)

6. Brewer, P., Speh, T.: Using the balanced scorecard to measure supply chain performance. Journal of Business Logistics 22, 75--93 (2000)

7. Gunasekaran, A, Patel, C., McGaughey, R.E.: A framework for supply chain performance measurement. Int. J. Production Economics 87, 333--347 (2004)

8. Bhagwat, R., Sharma, M.H.: An application of the integrated AHP-PGP model for performance measurement of supply chain management. Production Planning \& Control 20, 678--690 (2009)

9. Camarinha-Matos, L.M., Abreu, A.: Performance indicators for collaborative networks based on collaboration benefits. Production Planning \& Control 18:7, 592--609 (2007)

10.Westphal, I., Thoben, K.-D., Seifert, M.: Measuring Collaboration Performance in Virtual Organizations. In: Camarinha-Matos, L.M. et al. (eds.) Establishing the Foundation of Collaborative Networks. pp. 33--42, Springer, Boston (2007)

11. Madhusudhana Rao, C., Prahlada Rao, K., Muniswamy, V.V.: Delivery Performance Measurement in an integrated Supply Chain Management: Case Study in Batteries Manufacturing Firm. Serbian Journal of Management 6 (2), 205--220 (2011) 